\title{
VEINTITRÉS AÑOS DE JURISPRUDENCIA DEL TRIBUNAL CONSTITUCIONAL SOBRE DERECHOS FUNDAMENTALES
}

\author{
MANUEL JIMÉNEZ DE PARGAY CABRERA
}

Presidente delTribunal Constitucional 


\section{SUMARIO}

I. IrRadiación de la Constitución en los años 80. II. El amparo, la activiDAD ESTADISTICAMENTE MÁS IMPORTANTE. III. LA PROTECCIÓN DE LOS DERECHOS FUNDAMENTALES A TRAVÉS DEL RECURSO DE AMPARO Y DEL RECURSO DE INCONSTITUCIONALIDAD. III.1. Características comunes. III.2. Complejidad generada por la pluralidad de vías de protección. III.3. Diferentes derechos fundamentales. IV. LA CUESTIÓN DE SI LA TABLA CONSTITUCIONAL DE DERECHOS FUNDAMENTALES ES CERRADA O ABIERTA. V. Cuestiones PENDIENTES. V.1. Matices en la subsidiariedad del recurso de amparo. V.2. La capacidad del Tribunal Constitucional para afrontar el incremento de recursos de amparo. 


\title{
VEINTITRÉS AÑOS DE JURISPRUDENCIA DEL TRIBUNAL CONSTITUCIONAL SOBRE DERECHOS FUNDAMENTALES $(*)$
}

\author{
POR \\ MANUEL JIMÉNEZ DE PARGAY CABRERA \\ Presidente del Tribunal Constitucional
}

\section{IRRADIACIÓN DE LA CONSTITUCIÓN EN LOS AÑOS 80}

A raíz de la aprobación de la Constitución en 1978 se va a producir, durante los años 80 , una auténtica revolución en nuestro ordenamiento, como consecuencia del carácter refundamentador de la Constitución y de su irradiación hacia todos los sectores del ordenamiento jurídico. En esa revolución jurídica jugó un papel muy destacado el Tribunal Constitucional, que, coherentemente con la propia Constitución, y en particular con sus artículos 9.1, 53 y Disposición Derogatoria y en definitiva con su razón de ser, proclamó la fuerza normativa de la Constitución desde sus primeras Sentencias. Dicha fuerza normativa pasó del Tribunal Constitucional al Tribunal Supremo y de ahí irradió hacia la totalidad de los órganos del Poder Judicial.

(*) Conferencia pronunciada en la clausura de los Cursos de la Universidad de Extremadura. Yuste, julio 2003. 
Puede decirse que el Tribunal Constitucional ha realizado tres funciones ${ }^{1}$ :

1) Una función depuradora, por vía de anulación o, en el juicio sobre la ley, por la declaración de inconstitucionalidad sobrevenida: consiste esta primera función en la expulsión del ordenamiento de los actos y normas contrarios a los derechos fundamentales, tanto al resolver recursos de amparo como cuestiones de inconstitucionalidad y recursos de inconstitucionalidad.

2) Una función impulsora o promotora, a través de pronunciamientos de "mera inconstitucionalidad". El Tribunal Constitucional ha actuado no sólo como juez del caso, sino que ha sugerido, de vez en cuando, en los fundamentos jurídicos de sus Sentencias, cambios futuros en el Ordenamiento, indicando la vía de una mejora constitucional, no política, de la ley, mejora que le corresponde llevar a término al legislador. Así ocurre cuando al conocer sobre la constitucionalidad de la ley concluye que la misma es inconstitucional, pero no la puede anular para no provocar vacíos ${ }^{2}$.

3) Una función reorientadora (sobre la jurisdicción), a través sobre todo de la "interpretación conforme» de la legislación. Ha de subrayarse que la labor delTribunal Constitucional tiene como destinatarios especiales a los jueces, a los que dirige sus criterios intrepretativos de la Constitución.

\section{EL AMPARO, LA ACTIVIDAD ESTADÍSTICAMENTE MÁS IMPORTANTE}

En la última Memoria publicada del Tribunal Constitucional, la relativa al año 2002, ingresaron en el mismo 61 recursos de inconsti-

1 «Veinte años de jurisprudencia del Tribunal Constitucional». Conferencia pronunciada por JIMÉNEZ CAMPO, Javier, en la Facultad de Derecho de la UNED en marzo de 2002. Ejemplar mecanografiado.

2 Lo que sucedió en la STC 45/1989, de 20 de febrero, relativa a determinados preceptos de la ley $48 / 1983$, de normas reguladoras del Impuesto sobre la Renta de las Personas Físicas, que no anuló todos los preceptos viciados, sino que se remitió al legislador para que adoptara las modificaciones o adaptaciones pertinentes en el régimen legal del IRPF. 
tucionalidad, 99 cuestiones de inconstitucionalidad, 10 conflictos positivos de competencias, ningún conflicto negativo de competencias, un conflicto en defensa de la autonomía local y 7.285 recursos de amparo. Estos últimos no dejan de aumentar: en 1997 fueron 5.391; en 2001, 6.786, 500 más en el año 2002.

En cuanto a las materias sobre las que recaen los recursos de amparo, siempre siguiendo la Memoria relativa al 2002, casi la mitad (2.943) es penal, siguiéndole en importancia la contencioso administrativa (más de la cuarta parte, 1.889), la civil (casi una sexta parte, 1.383), la social (casi una décima parte, 623) y siendo 29 los recursos de procedencia militar y sólo 4 los relativos a actos parlamentarios.

En cuanto a los derechos invocados, es importante subrayar que en el $80 \%$ de los recursos (5.622) se invocó el derecho a la tutela judicial efectiva sin indefensión del art. 24.1 CE.

Por otro lado, nuestro Tribunal Constitucional, si atendemos al número de Sentencias de condena que ha recibido del Tribunal Europeo de Derechos Humanos, desempeña satisfactoriamente su competencia de amparo de los derechos fundamentales. En el año 2002, España sólo mereció una Sentencia de condena frente a 6 de Alemania, 30 de Gran Bretaña, 61 de Francia (donde no existe recurso de amparo) y 325 de Italia (donde tampoco hay recurso de amparo).

\section{LA PROTECCIÓN DE LOS DERECHOS FUNDAMENTALES A TRAVÉS DEL RECURSO DE AMPAROY DEL RECURSO DE INCONSTITUCIONALIDAD}

La protección de los derechos fundamentales por medio del recurso de amparo y del recurso de inconstitucionalidad presenta características comunes; sin embargo, la existencia de las dos vías diferenciadas plantea algunos problemas ${ }^{3}$.

3 Jiménez CAmpo, Javier, Conferencia citada, y Aguiar de Luque, Luis, y Pérez TREMPS, Pablo: Veinte años de jurisdicción constitucional en España,Tirant lo BlanchInstituto de Derecho Público Comparado, Universidad Carlos III, Valencia, 2002, págs. 99 y ss. 


\section{III.1. Características comunes}

A) Es de resaltar, ante todo, la afirmación por el Tribunal de la eficacia inmediata de las normas sobre derechos fundamentales, eficacia que se proyecta no sólo sobre los jueces o aplicadores del derecho, sino también sobre el creador del derecho, censurando las omisiones del legislador. Así, en la temprana Sentencia 15/1982, de 24 de abril, cuando el legislador no había desarrollado el procedimiento para hacer efectivo el derecho a la objeción de conciencia para la prestación del servicio militar, nuestro Tribunal Constitucional otorgó el amparo a un objetor reconociéndole el derecho a que su incorporación filas se aplazara hasta que se configurara el procedimiento que pudiera conferir la plena realización del derecho del objetor. También en la STC 31/1994, de 31 de enero, el Tribunal Constitucional otorgó el amparo a unas emisoras de televisión local por cable cuyo cese en sus actividades y desmontaje habían sido dispuestos por carecer de autorización administrativa, no existiendo normativa que la regulara. En fin, la STC 254/1993, de 20 de julio se anticipó al legislador ordinario en el reconocimiento de la libertad informática, cuestión a la que me referiré más adelante.

B) Una segunda característica de la jurisprudencia de nuestro Tribunal Constitucional en la aplicación de derechos fundamentales ha sido su atención a los tratados internacionales sobre estas materias ratificados por España, en aplicación de lo preceptuado por el art. 10.2 CE. Es más, nuestro Tribunal ha llevado a cabo una interpretación extensiva de este último precepto considerando la jurisprudencia del Tribunal Europeo de Derechos Humanos para delimitar el contenido de los derechos. En este sentido, por ejemplo, la STC 36/1984, de 3 de marzo, se basó en la jurisprudencia del Tribunal de Estrasburgo para determinar el concepto de dilaciones indebidas. Y la STC 114/1984, de 29 de noviembre, puntualizó, en un asunto de posible violación de la intimidad y del derecho a la tutela judicial efectiva en un supuesto de despido, que la interpretación relevante, de acuerdo con el art. $10.2 \mathrm{CE}$, es sólo la jurisdiccional del Tribunal Europeo y no la del Comité de Ministros.

La doctrina del Tribunal Europeo de Derechos Humanos ha sido singularmente relevante en materia de escuchas telefónicas (como puede comprobarse en la STC 49/1999, de 5 de abril) o en materia de extradición (como se ve, por ejemplo, en la STC 91/2000, de 30 de marzo).

Por lo demás, la atención a los documentos internacionales hizo a nuestro Tribunal citar la Carta de Derechos Fundamentales de la 
Unión Europea, aún cuando no fuese derecho positivo (STC 292/2000, de 30 de noviembre, FJ 8$)^{4}$.

C) La tercera característica de la interpretación de las normas sobre derechos fundamentales es la relativización de los derechos contenidos en el Capítulo III del Título I CE. Con apoyo en el art. 53.3 CE, el Tribunal Constitucional ha deducido del art. 53.3 que en el Capitulo III del Título I no hay derechos subjetivos en sentido estricto ${ }^{5}$, no hay derechos que merezcan la calificación de fundamentales, denominación que la propia Constitución reserva a lo proclamado en otros preceptos: en los arts. 15 a 29 de la Constitución bajo el rótulo «los derechos fundamentales y de las libertades públicas".

En la STC 36/1991, de 29 de enero, FJ 5, con motivo de la delimitación del alcance del art. 39.4 de la Constitución, se dijo que «en general (art. 53.3 CE) los principios reconocidos en el Capítulo Tercero del Título I, aunque deben orientar la acción de los poderes públicos, no generan por sí mismos derechos judicialmente actuables". En la STC 14/1992, de 10 de febrero, FJ 11, se afirmó, respecto del art. 51.1 $C E$, relativo a la protección de los consumidores y usuarios, que "este precepto enuncia un principio rector de la política social y económica, y no un derecho fundamental. En fin, en la STC 199/1996, de 3 de diciembre, FJ 3 se estableció que «no puede ignorarse que el art. 45 de la Constitución enuncia un principio rector, no un derecho fundamental. Los Tribunales deben velar por el respeto al medio ambiente, sin duda, pero de acuerdo con lo que dispongan las leyes que desarrollen el precepto constitucional».

Ahora bien, los principios rectores, que tienen como destinatario al legislador, pueden, como tales principios, ser aplicados por elTribunal Constitucional en los recursos de inconstitucionalidad y en los conflictos de competencias. Incluso en el ámbito del amparo los principios rectores de política social y económica son de mención pertinente cuando aparecen como derechos conexos con otro derecho fundamental perfecto.

D) Una cuarta característica de la interpretación de las normas sobre derechos fundamentales es el reconocimiento de la interpreta-

4 Cfr. Alexandre, H., y Catalä i Bas: La (in)tolerancia en el Estado de Derecho, Ediciones R.G.B., Valencia, 2002, con interesantes observaciones sobre la Jurisprudencia del ETD y la delTC español.

5 Véase JIMÉNEZ CAMPO, Javier, «Comentario al art. 53 CE», en Comentarios a la Constitución Española de 1978, dirigidos por Óscar Alzaga Villaamil, Edersa, Madrid, 1996, págs. 439 y ss. 
ción más favorable al ejercicio de los derechos. Así por ejemplo, en la STC 66/1985, de 23 de mayo, en el recurso de inconstitucionalidad frente a la reforma de la LOTC que derogó el recurso previo de inconstitucionalidad, nuestroTribunal reconoció la doctrina del "mayor valor" de los derechos fundamentales ${ }^{6}$.

E) Una quinta característica de la interpretación de las normas de derechos fundamentales por parte de la jurisprudencia constitucional consiste en que nuestro Tribunal Constitucional, siguiendo la estela de la doctrina alemana, ha subrayado el doble carácter de los derechos fundamentales, objetivo y subjetivo. En este sentido, ya en la temprana STC 25/1981, de 14 de julio, que resolvió el recurso de inconstitucionalidad interpuesto por el Parlamento vasco contra la Ley Orgánica 11/1980, de 1 de diciembre, "Sobre los supuestos previstos en el art. 55.2 de la Constitución", esto es, sobre la suspensión de determinados derechos para personas determinadas, en relación con las investigaciones correspondientes a la actuación de bandas armadas o elementos terroristas, se dijo que:

6 En el mismo sentido, en la STC 110/1988, de 8 de junio, rechaza nuestro Tribunal determinada interpretación de un precepto de la LOPJ (del art. 240) por ser contraria al "principio de primacía de los derechos y libertades reconocidos en el Capítulo Segundo del Título I de la Constitución".

En la STC 23/1988, de 22 de febrero, considera acertada la postura de unTribunal al aplicar el principio de que los límites a los derechos fundamentales han de interpretarse con criterio restrictivo y en el sentido más favorable a la eficacia y a la existencia del derecho (en aquél caso, el derecho fundamental a la ejecución de una sentencia).

La STC $1 / 1989$, de 16 de enero, señala que la aplicación de la doctrina de la interpretación favorable a los derechos fundamentales presupone la existencia de alguna res dubia o de alguna variante en la interpretación de los preceptos legales. Doctrina que confirman las SSTC 32/1989, de 13 de febrero, y 34/1989, de 14 de febrero.

En fin, en la STC 183/2000, de 10 de julio, que reconoció el carácter discriminatorio de una indemnización por la extinción del contrato de trabajo en el seno de un expediente de regulación de empleo, que se había calculado sobre la base de un salario discriminatorio, se afirmó, frente a la argumentación de las Sentencias impugnadas, que se fundamentaban en el consentimiento de los perjudicados lo siguiente: «El Tribunal Europeo de Derechos Humanos [...] ha declarado que la renuncia al ejercicio de los derechos fundamentales, cuando es posible, ha de ser expresa y formulada en términos inequívocos: de lo contrario podrían legitimarse, a través de ella, situaciones contrarias a la dignidad humana (casos Barberá, Messegué y Jabardo, de 6 de diciembre de 1988, § 82, Oberschlick, de 23 de mayo de 1991, §. 51, F.C.B. c. Italia, de 28 de agosto de 1991, §§ 33 a 35, y Poitrimol, de 23 de noviembre de 1993, §31)». 
«En primer lugar, los derechos fundamentales son derechos subjetivos, derechos de los individuos no sólo en cuanto derechos de los ciudadanos en sentido estricto, sino en cuanto garantizan un status jurídico o la libertad en un ámbito de la existencia. Pero al propio tiempo, son elementos esenciales de un ordenamiento objetivo de la comunidad nacional, en cuanto ésta se configura como marco de una convivencia humana justa y pacífica, plasmada históricamente en el Estado de Derecho y, más tarde, en el Estado social de Derecho o el Estado social y democrático de Derecho, según la fórmula de nuestra Constitución (art. 1.1).»

F) Otra nota a destacar en la interpretación por parte del Tribunal de las normas sobre derechos fundamentales es que el Tribunal ha reconocido en determinados supuestos la eficacia de los derechos fundamentales en las relaciones entre particulares, entendiendo que la vulneración la lleva a cabo el órgano judicial que no restablece el derecho del demandante. Baste recordar al respecto la STC 47/1985, de 27 de marzo, que otorgó el amparo a una profesora frente a un centro educativo que la había despedido, vulnerando su libertad ideológica y su derecho a no ser objeto de discriminación por motivos ideológicos.

G) Debe destacarse, además de lo que acabo de apuntar, que elTribunal ha señalado que la defensa de los derechos por parte de los poderes públicos no se limita a la obligación de no lesionarlos o interferir en la esfera de los mismos, sino en la obligación, positiva, de contribuir a la eficacia de tales derechos y de los valores en que se fundamentan. En este sentido, cabe recordar la STC 53/1985, de 11 de abril, relativa al recurso de inconstitucionalidad contra el Proyecto de Ley Orgánica de Reforma del art. 417 bis del Código Penal, por el que se despenalizaba el aborto en determinados supuestos. En ella se recordó que los derechos fundamentales conllevan deberes positivos del Estado, como se desprende de los arts. $9.2 ; 17.4 ; 18.1$ y $4 ; 20.3$ y 27 CE y se añadió que: «De la significación y finalidades de estos derechos dentro del orden constitucional se desprende que la garantía de su vigencia no puede limitarse a la posibilidad del ejercicio de pretensiones por parte de los individuos, sino que ha de ser asumida también por el Estado. Por consiguiente, de la obligación del sometimiento de todos los poderes a la Constitución no solamente se deduce la obligación negativa del Estado de no lesionar la esfera individual o institucional protegida por los derechos fundamentales, sino también la obligación positiva de contribuir a la efectividad de tales derechos, y de los valores que representan, aun cuando no exista una pretensión subjetiva por parte del ciudadano. Ello obliga especialmente al legislador, 
quien recibe de los derechos fundamentales "los impulsos y líneas directivas", obligación que adquiere especial relevancia allí donde un derecho o valor fundamental quedaría vacío de no establecerse los supuestos para su defensa» (FJ 4).

\section{III.2. Complejidad generada por la pluralidad de vías de protección}

Expuestas las características comunes de la interpretación de las normas sobre derechos fundamentales, hay que anotar que la interpretación de las normas de derechos fundamentales presenta alguna complejidad como consecuencia de la existencia de una pluralidad de cauces de garantía. En este sentido son oportunas dos observaciones.

La primera es que el recurso de amparo no tiene por objeto la protección del contenido esencial de los derechos fundamentales. El concepto de contenido esencial, basta comprobarlo leyendo el art. 53.1 $C E$, es un concepto empleado por la Constitución para señalar el límite del legislador $y$, hoy por hoy, queda excluido el amparo frente a leyes.

La segunda observación consiste en que, aunque la existencia del Tribunal Constitucional puede crear la impresión de que el amparo está para la protección de toda la Constitución, ha de subrayarse que el recurso de amparo protege sólo los derechos fundamentales reconocidos en la Sección Primera del Capítulo Segundo delTítulo Primero (arts. 15 a $29 \mathrm{CE}$ ), más del derecho a la igualdad del art. $14 \mathrm{CE}$ y la objeción de conciencia a la prestación del servicio militar reconocida en el art. $30 \mathrm{CE}$. En cambio, el recurso de inconstitucionalidad y la cuestión de inconstitucionalidad están orientados a la garantía de todo el texto constitucional.

Esto ha dado lugar a algunas Sentencias que no comparto7. Por ejemplo, advierto una contradicción entre las SSTC 173/1996, de 31 de octubre, y 159/1997 de 2 de octubre. La primera consideró inconstitucional una ley que había creado un gravamen complementario de la tasa fiscal sobre los juegos de suerte, envite o azar por considerar-

7 Cfr. Manuel JiméneZ de PARGA: «Cuestiones disputadas en la jurisprudencia constitucional", en Anuario de Derecho Constitucional y Parlamentario, núm. 11, año 1999, Asamblea Regional de Murcia-Universidad de Murcia. 
la contraria al principio de seguridad jurídica, reconocido en el art. 9.3 $\mathrm{CE}$. La segunda Sentencia hubo de denegar el amparo solicitado frente a actos de aplicación de dicha ley porque no había vulneración de los arts. 14 a $30 \mathrm{CE}$.

Tan sorprendente jurisprudencia, que suponía basar una resolución judicial en un precepto legal declarado inconstitucional once meses antes, dio lugar a tres votos particulares, entre ellos el mío, al que además se adhirió otro Magistrado. En mi voto particular expliqué que compartía en esencia los argumentos de los restantes votos particulares, $y$ añadía algunos adicionales.

Lo argumentado en los otros votos particulares giraba en torno a lo preceptuado por el art. 164 CE y 38.1 LOTC. Según el art. 164.1, inciso tercero $C E$, las Sentencias delTribunal Constitucional que declaren la inconstitucionalidad de una ley o de una norma con fuerza de ley $y$ todas las que no se limiten a la estimación subjetiva de un derecho, tienen plenos efectos frente a todos. A tenor del art. 38.1 LOTC las Sentencias recaídas en procedimiento de inconstitucionalidad tendrán el valor de cosa juzgada, vincularán a todos los poderes públicos y producirán efectos generales desde la fecha de su publicación en el BOE. En aplicación de esos preceptos, la STC 173/1996, de 31 de octubre, debería haber desplegado sus efectos en el recurso de amparo que resolvió la STC 159/1997, de 2 de octubre.

A este razonamiento añadía en mi voto particular lo siguiente:

El art. 55.2 LOTC prevé la que algunos han llamado autocuestión de inconstitucionalidad, al establecer que "en el supuesto de que se estime el recurso de amparo porque la ley aplicada lesiona derechos fundamentales o libertades públicas, la Sala elevará la cuestión al Pleno que podrá declarar la inconstitucionalidad de dicha ley en una nueva Sentencia...", que en este caso la inconstitucionalidad de la ley ya se había decidido por parte del Tribunal, y que la expresión «derechos fundamentales y libertades públicas" no debe interpretarse en sentido restrictivo, pues la seguridad jurídica en nuestra Constitución es, por un lado, principio configurador o soporte estructural de la tutela judicial efectiva (derecho fundamental reconocido y protegido por el art. 24.1 CE) y, por otro lado, el marco esencial de las libertades públicas, que los ciudadanos no disfrutan cuando falta la seguridad jurídica.

En segundo lugar, argumentaba en mi voto que en aquel supuesto el recurrente había solicitado que se planteara cuestión de inconstitucionalidad y eso habría de tenerse en cuenta para modular los efec- 
tos del art. 40.1 LOTC, en que se basaba la mayoría y según el cual «las sentencias declaratorias de la inconstitucionalidad de leyes, disposiciones o actos con fuerza de ley no permitirán revisar procesos fenecidos mediante sentencia con fuerza de cosa juzgada en los que se haya hecho aplicación de las leyes, disposiciones o actos inconstitucionales, salvo en el caso de los procesos penales o contencioso-administrativos referentes a un procedimiento sancionador en que, como consecuencia de la nulidad de la norma aplicada, resulte una reducción de la pena o de la sanción o una exclusión, exención o limitación de la responsabilidad".

Añadía, en tercer lugar, que la jurisprudencia de nuestro Tribunal en forma tan reiterada que hacía innecesaria la invocación de la larga lista de Sentencias, exige que las resoluciones judiciales, y de forma especial las Sentencias, se apoyen en fundamentos jurídicos sólidos, no pudiendo considerarse como tal un precepto nulo, expulsado casi hacía un año del ordenamiento jurídico. En definitiva, no resultaba pacífico que en las Sentencias recurridas en amparo ante el Tribunal Constitucional por fundamentarse en un precepto inconstitucional, no se encontrara comprometido derecho fundamental alguno: la Sentencia del Tribunal a quo incurría, en el momento de dictarse la Sentencia de amparo, en violación de derecho a la obtención de una sentencia fundada en Derecho.

\section{III.3. Diferentes derechos fundamentales}

Otro dato que introduce complejidad a la hora de analizar la jurisprudencia constitucional sobre derechos fundamentales es que el Tribunal Constitucional ha configurado una división, a efectos de control, conforme a dos tópicos fundamentales de la ciencia jurídica de nuestro tiempo. Distingue entre derechos que exigen sólo una decisión razonada y razonable (respecto de los cuales el control es argumental y externo) y derechos que requieren, además una decisión proporcionada (control, por tanto, material e interno). Arquetipo del primer tipo de derechos serían el derecho a la tutela judicial efectiva (art. 24.1 CE) y el derecho a la igualdad (art. $14 \mathrm{CE}$ ). Modelo de los segundos, los derechos de los arts. 18 (honor, intimidad y propia imagen) y 20 (libertad de expresión, derecho de información) CE. 


\section{LA CUESTIÓN DE SI LATABLA CONSTITUCIONAL DE DERECHOS FUNDAMENTALES ES CERRADA O ABIERTA}

Me referiré ahora a cómo ha respondido la jurisprudencia constitucional a las nuevas exigencias sociales, habida cuenta de que los constituyentes fijaron una lista cerrada ${ }^{8}$ de derechos fundamentales, entendiendo ahora por tales los amparables ante el Tribunal Constitucional.

Ocurre, en efecto, que a diferencia de lo que acontece en otros textos constitucionales (por ejemplo, en los de Portugal o Argentina, siguiendo la senda de la Constitución de Estados Unidos) nuestra Constitución de 1978 no incluye una cláusula abierta, por más que consigne una amplia lista de derechos y libertades.

Se olvidó, o no quiso recogerse, la norma sabia contenida en la Enmienda IX de la Constitución norteamericana. Se dejó dicho allí: "La enumeración que se hace en esta Constitución no deberá interpretarse como denegación o menoscabo de otros derechos que conserva el pueblo". También en naciones tan próximas a nosotros como son Portugal y Argentina se incluyen cláusulas abiertas en sus textos constitucionales.

El art. 17 de la Constitución de Portugal, revisado en 1982, establece que uel régimen de derechos, libertades y garantías se aplica a los enunciados en el Título II y a los derechos fundamentales de naturaleza análogan. Se habla por ello en el pais vecino de derechos fundamentales en sentido material y de derechos fundamentales en sentido formal, así como de derechos extraconstitucionales o de derechos fundamentales atípicos. En definitiva lo que se pretende subrayar es que la Constitución incluye un catálogo inacabado, que ha de ser completado si otros derechos reclaman, con exigencias razonables, la tutela constitucional.

En Argentina, antes de la última reforma, la Constitución ya contenía un artículo, el 33, del siguiente tenor: "Las declaraciones, derechos y garantías que enumera la Constitución no serán entendidos como negación de otros derechos y garantías no enumerados; pero

8 Cfr. mi trabajo "La refundamentación del Ordenamiento jurídico", en los estudios en homenaje al Profesor Francisco Rubio Llorente La Democracia Constitucional, Congreso de los Diputados, etc., Madrid, 2002, pás. 131-142. También en Persona y Derecho, núm. 44, 2001, págs. 17-34. 
que nacen del principio de la soberanía del pueblo y de la forma republicana de gobierno". Si pasamos por alto esta concesión a "la forma republicana", tan cara a los franceses y que resulta desmentida con la presente Monarquía española, lo que nos importa consignar es que la doctrina argentina consideró los derechos extraconstitucionales antes de 1994. Fueron catalogados derechos explícitos, derechos no enumerados provenientes del derecho natural y derechos imputados o creados por la jurisprudencia.

La última clase de derechos (los creados por la jurisprudencia) tiene especial relieve. Los derechos no escritos han de ser tutelados por la jurisprudencia, ya que las Constituciones proporcionan al intérprete un punto de apoyo, unas palabras (escasas a veces, lapidarias), sobre los que hay que efectuar, mediante una actividad creadora, la construcción del derecho fundamental.

Debido al lejano momento histórico de la elaboración de la Constitución de Estados Unidos, los jueces se han visto allí obligados a incorporar al acervo constitucional diversos derechos que no figuran ni en los textos del siglo XVIII ni en las Enmiendas posteriores: desde el derecho a la presunción de inocencia al derecho de asociación, pasando por el derecho a casarse y el de educar libremente a los hijos. Y la jurisprudencia norteamericana nos ofrece curiosos ejemplos de tutela judicial que fue articulada apoyándose en otros derechos expresamente protegidos por la Constitución.

Suele citarse una Sentencia de 1965, dictada en Griswold v. Connecticut, donde se consideró violado el derecho a la privacidad en el matrimonio, invocando al efecto las Enmiendas Primera (que se refiere a varios derechos, entre ellos el de libertad religiosa), Tercera (no alojar tropas sin el consentimiento del dueño de la casa), Cuarta (inmunidad del hogar), y Quinta (garantías del imputado). Con estos derechos se argumentó que proporcionar información sobre el uso de contraconceptivos, que es lo que hacía el Sr. Griswold, director de una liga de planeamiento familiar, conculcaba el derecho a la privacidad en el matrimonio. La Enmienda Novena, al dejar abierta la lista de derechos fundamentales, facilitó esta elaboración jurisprudencial de un derecho atípico.

Algo parecido se ha llevado a cabo por la interpretación constitucional en Italia y en Alemania, cuyas constituciones contienen unos preceptos que han facilitado la inclusión de nuevos derechos: art. 2 de la Constitución italiana; art. 2.1 de la Ley Fundamental de Alemania. 
Pues bien, en la Constitución española cabe hablar de algunos derechos no enumerados de forma expresa en el texto constitucional.

Es el caso del derecho de rectificación, del principio non bis in idem y de la libertad informática.

El derecho de rectificación, no reconocido en el texto fundamental, apareció primero en alguna sentencia del Tribunal Constitucional (v. gr. STC 35/1983, de 11 de mayo) y luego fue desarrollado por la Ley Orgánica 2/1984, de 26 de marzo.

Por otra parte, ha de recordarse que desde la STC 2/1981, de 30 de enero, nuestro Tribunal Constitucional ha reconocido que el principio non bis in idem integra el derecho fundamental al principio de legalidad en materia penal y sancionadora (art. 25.1 CE) a pesar de su falta de mención expresa en dicho precepto constitucional, dada su conexión con las garantías de tipicidad y de legalidad de las infracciones. En este sentido el Tribunal ha declarado que este princípio veda la imposición de una dualidad de sanciones "en los casos en que se aprecie la identidad de sujeto, hecho y fundamento" (por todas, SSTC $2 / 1981$, de 30 de enero, FJ 4 y 2/2003, de 16 de enero, FJ 3). Recientemente en la STC $2 / 2003$, de 16 de enero el Tribunal ha resumido su doctrina al respecto.

$Y$ junto al derecho de rectificación y al principio non bis in idem he de hacer aquí una alusión breve a la jurisprudencia de nuestro Tribunal Constitucional sobre otro derecho no reconocido en el texto de la Constitución: el derecho a la libertad informática.

En un voto particular a la STC $290 / 2000$, de 30 de noviembre, señalé que aunque compartía el fondo de la Sentencia, consideraba que el Tribunal debía haber aludido en ella al reconocimiento y protección de un derecho fundamental, el derecho de libertad informática, que no figura en la Tabla de nuestro texto de 1978. Y señalaba los mimbres con los que se podía construir: consideraba esencial el art. 10.1 CE y su reconocimiento de la dignidad de la persona, como eje vertebrador y fuente de consistencia constitucional de ese derecho. Aludia también a otros preceptos constitucionales y aTratados y Acuerdos Internacionales, así como a Derecho derivado comunitario europeo, como guías de la interpretación constitucional en la cuestión (con base en el art. 10.2 CE).

Como alli recordaba, fue la STC 254/1993, de 20 de julio, la que mencionó, por vez primera en nuestra jurisprudencia, la libertad informática, entendida como un derecho fundamental "en sí mismo». Se trataba de un supuesto en que un ciudadano fundamentó su solicitud 
de amparo en el art. 18.4 CE, que no reconoce propiamente un derecho fundamental, sino que formula en sentido estricto un mandato al legislador al decir que "la ley limitará el uso de la informática para garantizar el honor y la intimidad personal y familiar de los ciudadanos $y$ el pleno ejercicio de sus derechos".

Lo dicho en aquella primera Sentencia de 1993 se fue perfilando en otras posteriores. Así, en la relativa a las normas reguladoras del número de identificación fiscal (STC 143/1994, de 9 de mayo). O en las que declararon contrario a la libertad sindical (art. $28 \mathrm{CE}$ ) en relación con el anteriormente citado art. 18.4 de nuestra Carta Magna el uso por una empresa del dato de la afiliación sindical para detraer haberes de los trabajadores con ocasión de una huelga promovida por un sindicato determinado (entre las que destacan la STC 11/1998, de 13 de enero, que fue la primera, y la STC 94/1998, de 4 de mayo).También en la STC 202/1999, de 8 de noviembre, en la que, con ocasión de la denegación a un trabajador de la cancelación de sus datos médicos en un fichero informatizado de una entidad de crédito sobre bajas por incapacidad temporal, se apreció que el almacenamiento sin cobertura legal en soporte informático de los diagnósticos médicos del trabajador sin mediar su consentimiento expreso constituía una desproporcionada restricción del derecho fundamental a la protección de datos personales.

El 30 de noviembre de 2000 nuestro Alto Tribunal aprueba dos importantes Sentencias, la 290 y $292 / 2000$. La primera de ellas, que es la que contiene el voto particular citado, resuelve varios recursos de inconstitucionalidad sobre determinados preceptos de la Ley Orgánica 5/1992, de 29 de octubre, de Regulación del Tratamiento Automatizado de Datos de Carácter Personal (LORTAD). Cuando se aprobó la Sentencia, la LORTAD ya había sido derogada por la hoy vigente Ley Orgánica 15/1999, de 23 de diciembre, de Protección de Datos de carácter Personal (LOPD). No sorprende, pues, que el fallo declarara la pérdida sobrevenida del objeto de dos de los recursos planteados. Por lo demás, se desestimaron los otros dos recursos de inconstitucionalidad planteados.

La segunda de las Sentencias destacadas, la 292/2000, resuelve un recurso de inconstitucionalidad planteado contra ciertos incisos de determinados artículos de la mencionada Ley Orgánica de Protección de Datos de Carácter Personal y contiene una recapitulación y desarrollo del derecho a la libertad informática en nuestra jurisprudencia constitucional.

Destacaré solamente que la Sentencia subraya que junto a los datos que son protegidos en virtud del reconocimiento constitucional 
del derecho a la intimidad en el art. $18.1 \mathrm{CE}$, la protección constitucional va más allá, comprendiendo lo que en ocasiones nuestro Tribunal ha definido en términos más amplios como esfera de los bienes de la personalidad que pertenecen al ámbito de la vida privada, inextricablemente unidos al respeto a la dignidad personal y al pleno ejercicio de los derechos de la persona. De este modo, afirma nuestroTribunal, el objeto de protección del derecho fundamental a la protección de datos no se reduce sólo a los datos íntimos de la persona, sino a cualquier tipo de dato personal, sea o no intimo, cuyo conocimiento o empleo por terceros pueda afectar a sus derechos, sean o no fundamentales, porque su objeto no es sólo la intimidad individual, que para ello está la protección que el art. 18.1 CE otorga, sino los datos de carácter personal. Por consiguiente, también alcanza a aquellos datos personales públicos, que por el hecho de serlo, no escapan al poder de disposición del afectado porque así lo garantiza su derecho a la protección los relativos a la vida privada o íntima de la persona, sino que los datos amparados son todos aquellos que identifiquen o permitan la identificación de la persona, pudiendo servir para la confección de su perfil ideológico, racial, sexual, económico o de cualquier otra índole, o que sirvan para cualquier otra utilidad que en determinadas circunstancias constituya una amenaza para el individuo.

Con el reconocimiento de este derecho, nuestroTribunal ha cumplido una de las tareas más importantes de los Tribunales Constitucionales: extender la tutela a determinadas zonas del Derecho no expresamente consideradas en las correspondientes Constituciones cuando, como ocurre en este caso, es necesario hacerlo para que no queden a la intemperie, sin techo jurídico alguno, intereses esenciales de los ciudadanos.

\section{CUESTIONES PENDIENTES}

\section{V.1. Matices en la subsidiariedad del recurso de amparo}

Entre las cuestiones pendientes que plantea la protección de los derechos fundamentales y en particular el recurso de amparo, quiero traer aquí a colación una muy concreta, que tiene como presupuesto la continuación del recurso de amparo tal y como viene regulado en la actualidad y que incide igualmente en la siempre abierta cuestión de la relación entre la jurisdicción ordinaria y el Tribunal Constitucional. Me refiero a la interpretación de la subsidiariedad del recurso de amparo que sostuve en mi voto particular a la STC 63/1996, de 16 de abril. 
Constituían el objeto de aquel recurso de amparo tres concretas resoluciones dictadas por un Juzgado de Instrucción y una Audiencia Provincial por las que se denegaba la nulidad de actuaciones solicitada por el demandante en unas diligencias previas, a las cuales se reprochaba la vulneración del derecho a un proceso con todas las garantías (art. 24.2 CE) y más concretamente en su doble vertiente de derecho a un juez imparcial y al principio acusatorio. También invocaba el recurrente la lesión del derecho fundamental que consagra el art. 24.1 CE, por cuanto la investigación sumarial ilimitada e inquisitorial de que estaba siendo objeto en las mencionadas diligencias había provocado al mismo una manifiesta situación de indefensión proscrita por el mencionado precepto constitucional.

La mayoría del Tribunal decidió dictar sentencia inadmitiendo el recurso de amparo por entender que se había incumplido el requisito que establece el art. 44.1 a) LOTC - agotamiento de la vía judicial previa - y, en consecuencia, concurría la causa de inadmisión prevista en el art. 50.1 a) LOTC en relación con el anterior precepto; que de este modo procedía a declarar en aquella fase procesal del recurso de amparo la inadmisión, pues el recurrente había planteado su queja frente a resoluciones dictadas en una fase previa del proceso penal (diligencias previas), anterior a la apertura y sustanciación del acto del juicio, $y$, por ende, a la resolución del proceso, de forma que todavía tenía ocasión el demandante de plantear las vulneraciones constitucionales denunciadas, así como el órgano judicial de pronunciarse sobre las mismas y, eventualmente, proceder a su reparación.

Mi discrepancia del parecer mayoritario de la Sala se fundamenta en varias razones:

Pienso que no debió considerarse extemporáneo, por prematuro, este recurso de amparo. Reconozco la subsidiariedad del recurso de amparo. El art. 44.1 a) LOTC lo configura con ese carácter. No admito, sin embargo, una interpretación rígida de tal precepto que infravalore, o desconozca, otras normas de la misma Ley.

El art. 49.1 LOTC precisa que en las demandas de amparo «se fijará con precisión el amparo que se solicita para preservar o restablecer el derecho o libertad que se considere vulneradon. La finalidad, pues, de este proceso es tanto "preservar" como "restablecer". El art. 41.3 LOTC menciona el mismo doble objetivo («establecer o preservar") al referirse a las pretensiones del amparo constitucional y el art. 54 LOTC vuelve a señalar la preservación de los derechos y libertades, junto al restablecimiento de ellos, como función de la Sala que conozca recursos de amparo "respecto de decisiones de los Jue- 
ces y Tribunales", que es, precisamente, la función que en este caso asume nuestro Tribunal.

"Preservar", según el Diccionario de la Academia, es "poner a cubierto anticipadamente a una persona o cosa, de algún daño o peligro». ¿Cómo puede preservarse un derecho, o una libertad, transcurrido mucho tiempo (varios años acaso) desde que la violación se produjo? ¿Debemos olvidarnos de la misión de preservación que nuestra Ley Orgánica nos encomienda? ¿Hemos de esperar, paciente y pasivamente, al agotamiento de «todos los recursos utilizables dentro de la vía judicial», a lo largo de un tiempo considerablemente más dilatado en la práctica que el previsto en las normas procesales, y, mientras tanto, inadmitir los recursos de amparo por considerarlos prematuros?

El art. 44.1 a) LOTC es claro y terminante al establecer los requisitos del recurso. Pero los citados arts. $41.3,49.1$ y 54 LOTC también lo son al definir el sentido y el alcance del amparo constitucional. ¿Cómo resolver la aporía que plantea una interpretación global y sistemática de tales normas?

Mi respuesta es que debemos utilizar criterios flexibles, que tengan en cuenta las circunstancias de cada supuesto enjuiciado. La subsidiariedad, desde luego, no es un dogma que, como tal, sea intocable, ni es una regla que deba aplicarse inexorablemente, sin dejarse vencer a los ruegos de excepciones. Una excepción, a nuestro entender, la constituía el recurso resuelto en la STC 63/1996 (como se desprende de los hechos recogidos en los antecedentes de la Sentencia), y otras excepciones fueron las situaciones de quejosos que se encontraban privados de libertad y a los que el Tribunal Constitucional otorgó el amparo con una interpretación flexible de la regla de la subsidiariedad (por ejemplo, STC 128/1995).

Ante la posible conculcación grave de derechos fundamentales cuya preservación se ha frustrado en la vía judicial, el recurso de amparo debe ser admitido, sin aguardar al agotamiento de todos los recursos utilizables ante Jueces y Tribunales.

He escrito, repito, "conculcación grave de derechos fundamentales cuya preservación se ha frustrado en la vía judicial». Mi interpretación (que no coincide con la de la mayoría de la Sala) considera el supuesto en el que se dió ocasión a los Jueces y Tribunales, al resolver los pertinentes recursos, de reparar las graves violaciones por ellos mismos cometidas o por órganos judiciales inferiores. Fue la tesis que latía en la STC 78/1994 (fundamento jurídico $2 .^{\circ}$ ). Una actitud distinta 
habrá de adoptarse si el recurrente en amparo no da oportunidad a los Jueces y Tribunales de preservar los derechos y libertades, acudiendo prematuramente -en estos casos, sí- al Tribunal Constitucional.

Procedente es distinguir, en suma, entre dos clases de recursos de amparo, vistos desde la posible extemporaneidad de los mismos: A) Recursos que, sin pronunciamiento revisorio en la vía judicial, se presentan per saltum al Tribunal Constitucional; B) Recursos de amparo contra actos lesivos de derechos fundamentales de naturaleza procesal no susceptibles de ser reparados en la Sentencia firme y que pusieron fin a un incidente, o a una petición autónoma dentro de un proceso principal, es decir, aquéllos en los que los Jueces y los Tribunales desaprovecharon la oportunidad de preservar y restablecer los derechos fundamentales, si habían sido violados por ellos o por un órgano inferior; resoluciones, además, contra las que no es legalmente permitido, de momento, un recurso que pudiera preservar y restablecer, en la vía judicial, el derecho o la libertad violados.

Mientras que deben inadmitirse, por prematuros, los del apartado A), y en estos supuestos aplicar inflexiblemente el principio de subsidiariedad, los recursos del apartado B), en los que se dió a Jueces y Tribunales la oportunidad de remediar las infracciones, como es el caso de la STC 63/1996, deben ser admitidos.

La lectura de los antecedentes de la Sentencia ilustra suficientemente de los afanes del quejoso para que el Juzgado de Instrucción y la Audiencia Provincial tutelasen sus derechos fundamentales (18 de mayo de 1990: petición al Juzgado de la nulidad de las actuaciones; 12 de julio de 1990: reiteración de la petición; 20 de julio de 1990: resolución denegatoria del Juzgado; 16 de octubre de 1990: Auto desestimando el recurso de reforma; 7 de diciembre de 1990: Auto de la Audiencia desestimatorio del recurso de queja). No cabe decir que, en este caso, dejó de darse a los Jueces y Tribunales la oportunidad de pronunciarse sobre la violación de los derechos fundamentales. Por otra parte, la lesión de su derecho fundamental, el de defensa, es autónoma, no se identifica con la presunción de inocencia, ni es susceptible de ser reparada en la Sentencia, pues se produce por el solo hecho de permanecer el recurrente sujeto a ese grave "drama" que supone una instrucción abierta, sin siquiera conocer las causas por las que pueda oponerse a ella.

La subsidiariedad del amparo constitucional fue, pues, respetada por el recurrente. Acudió a nuestro Tribunal después de pretender infructuosamente, en la vía judicial, la preservación, primero, y el restablecimiento, más tarde, de sus derechos básicos. El Auto final, de 7 
de diciembre de 1990, no es recurrible anteTribunal alguno de la jurisdicción ordinaria.

Se respetó la subsidiariedad y la violación de derechos fundamentales fue "grave". Es otro requisito que consignamos en nuestra posición a favor de una interpretación flexible de la exigencia del art. 44.1 a) LOTC. La simple lectura de los antecedentes expuestos en la Sentencia de la mayoría nos advierte de la gravedad de las conculcaciones cometidas. Un examen de las actuaciones judiciales confirma plenamente esa impresión.

De secundar, por otra parte, este Tribunal para el futuro la tesis de la mayoría, en estos casos de inquisiciones generales, no se podrá restablecer, en la práctica, por los Jueces constitucionales, el derecho de defensa fundamental vulnerado, ya que, si una inquisición general (con todas sus secuelas, como lo son la obligación de comparecer apud acta cada quince días, embargo de todas las cuentas y patrimonio del imputado, retención del pasaporte, etc.), finaliza con un Auto de sobreseimiento o una Sentencia absolutoria, no podrá nunca este Tribunal cumplir con su obligación de preservar y restablecer los derechos fundamentales, aún cuando se le haya dado posibilidad a los Tribunales ordinarios de pronunciar "su primera palabra" en esta materia.

Estas son las razones en las que baso esta interpretación de la subsidiariedad del recurso de amparo. Posteriormente, en mi voto particular a la STC 41/1998, de 24 de febrero, que hubo de intentar resolver el mismo asunto, infructuosamente a mi juicio, me remití al voto particular que acabo de exponer.

\section{V.2. La capacidad del Tribunal Constitucional para afrontar el incremento de recursos de amparo}

Pero la gran cuestión pendiente que plantea hoy el recurso de amparo es la de si el Tribunal va a poder seguir dando respuesta al enorme volumen de recursos que se presentan. En el año 2002 ingresaron en elTribunal 7.546 asuntos, de los que la mayoría (7.285) fueron recursos de amparo. El conjunto de resoluciones definitivas dictadas por elTribunal Constitucional en ese mismo periodo ascendió a 5.671, claramente por debajo de las ingresadas y también del límite de las 6.000 alcanzado en los dos años anteriores.

Entre las soluciones que se han avanzado destacaré dos. 
Una es muy sencilla, puede ponerla en marcha elTribunal sin necesidad de reforma legislativa y parece inevitable: consiste en aumentar el número de Letrados del Tribunal, toda vez que el de Magistrados viene establecido por la Constitución.

Otra es la que propuso el Presidente del Tribunal Supremo y del Consejo General del Poder Judicial, Pascual Sala Sánchez, en los discursos de apertura del Año Judicial de $1994^{9}$ y de $1995^{10}$. Consistiría en eliminar el recurso de amparo ante el Tribunal Constitucional por acciones y omisiones de órganos jurisdiccionales que vulneraran el derecho a la tutela judicial efectiva del art. 24 CE. Basaba el Presidente del Tribunal Supremo la constitucionalidad de su postura en que el art. 53.2 CE lo que establece en todo caso es la protección de las libertades y derechos reconocidos en el art. 14, la Sección Primera del Capítulo II del Título Primero y la objeción de conciencia del art. 30, ante los Tribunales ordinarios por un procedimiento basado en los principios de preferencia y sumariedad. Pero el recurso de amparo ante el Tribunal Constitucional sólo existirá, según el art. 53.2 CE, "en su cason. A lo que añadía Pascual Sala que el art. 161.1 b) CE le atribuye alTribunal Constitucional el conocimiento del recurso de amparo "en los casos y formas que la ley establezca».

El recurso de amparo, en suma, con las modificaciones en su regulación que pueden ( $y$ deben) introducirse, es una pieza esencial para la protección de los derechos fundamentales. Sin él nuestro Estado de Derecho se desfiguraría.

Son muchos los recursos de amparo que se presentan. Pero no resulta procedente limitar el número fijando un mínimo de cuantía.

9 "La delimitación de funciones entre las jurisdicciones constitucional y ordinaria en la protección de los derechos fundamentales». Discurso leído por el Presidente delTribunal Supremo y Presidente del Consejo General del Poder Judicial, Excmo. Sr. D. Pascual Sala Sánchez, en el solemne acto inaugural del Año Judicial celebrado en el Palacio de Justicia el día 12 de septiembre de 1994. Madrid, 1994.

10 "La posición constitucional delTribunal Supremo". Discurso leído por el Presidente del Tribunal Supremo y Presidente del Consejo General del Poder Judicial, Excmo. Sr. D. Pascual Sala Sánchez, en el solemne acto inaugural del Año Judicial celebrado en el Palacio de Justicia el día 14 de septiembre de 1995, Madrid, 1995. 
Los derechos fundamentales no son cuantificables. Precisamente las batallas jurídicas más estimables son, a veces, aquellas en las que se lucha sin pretensiones económicas, o éstas son de escasa importancia.

Hay que mantener el recurso de amparo. Los españoles somos ahora plenamente ciudadanos. Hemos de seguir viviendo $y$ conviviendo en un Estado social y democrático de Derecho. La condición de súbditos pertenece al pasado. 